\section{Benzodiazepines: time for reassessment ${ }^{\dagger}$}

\author{
D. D. R.WILLIAMS and ANDREW MCBRIDE
}

The natural history of a new drug can be divided into three distinct phases. The first is its introduction with publicity, even hype and exaggerated expectation. The second phase is very different, new problems are identified and uncertainty develops about its role and usefulness. The third phase is the eventual resolution of the uncertainty about the new product by a clearer definition of the indications for its use, cautions, contraindications and side-effects. Some drugs are abandoned completely. The debate over benzodiazepines has never properly been resolved, with clinicians divided into advocates, opponents and perhaps the majority who use benzodiazepines reluctantly. Are we now at a stage when this third phase can be spelt out with greater clarity?

\section{BACKGROUND}

The benzodiazepines were developed in the 1950s and many were introduced in the 1960s (Lader, 1991). These drugs have anxiolytic, hypnotic, muscle relaxant and anticonvulsant actions. They soon became popular drugs, widely prescribed in general practice as hypnotics and anxiolytics. This popularity arose from their apparent effectiveness and low toxicity compared with barbiturates. By the late 1970s, concerns were raised about cognitive and motor impairment, the sheer extent of prescribing in primary care (peaking at more than $\mathbf{3 0}$ million prescriptions in the UK in 1979) and the emergence of small numbers of patients complaining of iatrogenic dependence, leading eventually to a mass legal action in 1992. The misuse of diverted benzodiazepines by polydrug and alcohol misusers also gives continuing reason for concern (Ciraulo $e t$ al, 1988; Strang et al, 1994).

\footnotetext{
'See pp. 433-438, this issue.
}

\section{CSM GUIDELINES}

The Committee on the Safety of Medicines (CSM, 1988) reacted to the concerns by spelling out emphatic guidelines about the use of benzodiazepine drugs.

\section{Benzodiazepines as anxiolytics}

(a) Benzodiazepines are indicated for the short-term relief (two to four weeks only) of anxiety that is severe, disabling or subjecting the individual to unacceptable distress occurring alone or in association with insomnia or short-term psychosomatic, organic or psychotic illness.

(b) The use of benzodiazepines to treat short-term mild 'anxiety' is inappropriate and unsuitable.

\section{Benzodiazepines as hypnotics}

(c) Benzodiazepines should be used to treat insomnia only when it is severe, disabling or subjecting the individual to extreme distress. The lowest dose should be used and treatment should not be continued beyond four weeks.

A number of psychiatrists found these guidelines and those of the Royal College of Psychiatrists (1988) an inhibiting and constraining influence on good psychiatric practice. Many others and a significant percentage of family doctors reacted to these guidelines by a rapid reduction in the use of these drugs and their virtual elimination from their practice. In turn, a wide range of other drugs were used to treat anxiety and insomnia such as the phenothiazines, beta-blockers and antidepressant drugs including tricyclics and, more recently, selective serotonin reuptake inhibitors.

Many doctors feel that it is their continuing responsibility to implement the CSM guidelines. Taylor et al (1998, this issue) confirm this approach. In an excellent epidemiological study of the use of benzodiazepines in Liverpool, they conclude that older people still use benzodiazepines contrary to official guidelines and that their findings add weight to the opinion that persistent and long-term use should be discouraged.

\section{CONTEMPORARY PERSPECTIVE}

The CSM guidelines may have been appropriate in 1988 but now need to be modified in the light of the experience gained over the past 10 years. Two new perspectives have emerged.

The original guidelines limiting the use of benzodiazepines as hypnotics to only two to four weeks seem harsh. The causes of severe disabling insomnia are most commonly personal problems, organic or psychiatric disease. These difficulties do not resolve themselves in two to four weeks. Sleep is essential for well-being. Greater emphasis needs to be placed on the importance of high-quality sleep (Oswald, 1986) - a fact that has to be pointed out to some colleagues. The primary responsibility of the doctor is the best treatment for each individual patient and it is not merely to reduce psychotropic medication according to government sponsored guidelines.

The use of benzodiazepines in shortterm mild anxiety should be approached with caution, but there is a role for these drugs in anxiety disorders as described by Shader \& Greenblatt (1993) in a review of the subject.

Psychological approaches to anxiety and insomnia are neither available to nor appropriate for many people with longstanding problems. Even when appropriate, alternative drug therapies are invariably more hazardous, less acceptable to patients, slower in onset and less effective against the target symptoms. They are also usually much more expensive.

The prescription of benzodiazepines for self-limiting reactive problems is both unnecessary and undesirable (Catalan et al, 1984). In psychiatric practice the balance between the relief of symptoms and suffering and the risks of side-effects is a familiar one with most groups of drugs, and the benzodiazepines are arguably the safest, and invariably the least resisted by patients. It is now the case that most longterm users are elderly and infirm, but untroubled and unconcerned by their benzodiazepine use (Wright et al, 1994). 
Withholding benzodiazepines from patients with psychiatric illness or withdrawing long-term users in the absence of risk cannot be justified (Kräupl Taylor, 1989), although patients need to have possible problems discussed as with any other treatment.

\section{REFERENCES}

Catalan, J., Gath, D., Edmonds, G., et ol (1984) The effects of non-prescribing of anxiolytics in general practice. I. Controlled evaluation of psychiatric and social outcome. British Journal of Psychiatry, 144, 593-602.

Ciraulo, D. A., Sands, B. F. a Shader, R. I. (1988) Critical review of liability for benzodiazepine abuse among alcoholics. American Journal of Psychiatry, 145. 1501-1506.

Committee on the Safety of Modicines (1988) Benzodiazepines, dependence and withdrawal symptoms. Current Problems, 21, I-2.

D. D. R.WILLIAMS, FRCPsych, Cefn Coed Hospital, Swansea; ANDREW MCBRIDE, MRCPsych, Community Addictions Unit, Canton, Cardiff

Correspondence: Dr D. D. R. Williams, Consultant Psychiatrist, Cefn Coed Hospital, Swansea SA2 0GH. Tel: 01792 516475; Fax: 01792516410

(First received 21 July 1998, final revision 21 July 1998, accepted 12 August 1998)

Kräupl Taylor, F. (1989) The damnation of benzodiazepines. British Journal of Psychiatry. 154 697-704.

Lader, M. (1991) History of benzodiazepine dependence. Journal of Substance Misuse Treatment. 8. 53-59.

Oswald, I. (1986) Drugs for poor sleepers? British Medical Journal, 292. 715.

Royal College of Pyychiztrists (1988) Benzodiazepines and dependence: A College statement. Psychiatric Bulletin, 12, 107-109.
Shader, R. I. \& Greenblatt, D. J. (1993) Use of benzodiazepines in anxiety disorders. New England Journal of Medicine, 328, 1398-1405.

Strang, J., Griffiths, P., Abbey, J., et al (1994) Survey of use of injected benzodiazepines among drug users in Britain. British Medical Journal, 308, 1082.

Taytor, S., McCraben, C. F. M., Wikon, K. C. M., et al (1998) Extent and appropriateness of benzodiazepine use: Results from an elderly urban community. British Journal of Psychiatry, 173, 433-438.

Wright, N., Caplan, R. \& Payne, S. (1994) Community survey of long-term daytime use of benzodiazepines. British Medical Journal, 309, 27-28. 